\title{
Intercellular adhesion molecule 1 (ICAM-1) in the pathogenesis of mononuclear cell alveolitis in pulmonary sarcoidosis
}

\author{
Klaus Dalhoff, Sabine Bohnet, Jörg Braun, Burkhard Kreft, Karl J Wießmann
}

\begin{abstract}
Background-Alveolitis in pulmonary sarcoidosis is characterised by an accumulation of highly activated macrophages and CD4 + lymphocytes in the alveolar compartment. The role of intercellular adhesion molecule 1 (ICAM-1) expression on alveolar cells has been studied in this context.

Methods-Using a sandwich ELISA technique, ICAM-1 expression on alveolar macrophages from 17 consecutive untreated patients with pulmonary sarcoidosis and six healthy normal volunteers was quantified. In addition, parameters of macrophage activation (tumour necrosis factor $a$ (TNF $a$ ) and superoxide anion release) were
\end{abstract} evaluated.

Results-Significantly elevated expression could be demonstrated on alveolar macrophages from patients with pulmonary sarcoidosis compared with healthy controls (mean (SD) $0.74(0.24)$ ELISA units (EU) $v 0.46(0.12)$ EU). On subdividing the patients into those with active and those with inactive disease, only the former showed increased ICAM-1 levels on alveolar macrophages $(0.82(0.27) \mathrm{EU})$ compared with control alveolar macrophages. No differences were detected in serum levels of soluble ICAM-1 between patients and controls. ICAM-1 expression on alveolar macrophages from patients with sarcoidosis correlated with the spontaneous release of TNF $a$ but not with the release of the superoxide anion by the activated macrophages. There was no correlation with the percentage of lymphocytes or the absolute number of CD4 + cells in bronchoalveolar lavage fluid.

Conclusions-Increased ICAM-1 surface expression on alveolar macrophages reflects disease activity in the pulmonary compartment. Considering the significance of adhesion molecules during antigen presentation and lymphocyte activation, ICAM-1 expression on alveolar macrophages may have an important role in the immune process of pulmonary sarcoidosis.

(Thorax 1993;48:1140-1144)
Leucocyte homing to sites of acute or chronic inflammation is a crucial step during the $\vec{x}$ inflammatory response. Adhesion molecules ${ }_{\infty}^{+}$ such as intercellular adhesion molecule $1-\vec{J}$ (ICAM-1) play a major part in this process by mediating adherence of leucocytes to the $\vec{P}$ endothelium and initiating the extravasation of those cells. ${ }^{1}$ At the site of inflammation the interaction of ICAM-1 (CD54) with its ligands LFA-1 (CD11a/CD18) and Mac-1 (CD11b/CD18) provides an antigen indepen- $\frac{\Phi}{3}$ dent mechanism of cell-cell activation in addition to the antigen dependent interaction mediated by molecules of the MHC class II complex and the $T$ cell receptor. ${ }^{2}$ Under ${ }^{\mathrm{C}}$ normal conditions the $\beta_{2}$ integrins, which are restricted to leucocytes, exist in an inactive form. They are activated rapidly by a number of substances including lipopolysaccharide $\frac{0}{\circ}$ (LPS) and phorbol-12-myristate-13-acetate (PMA) ${ }^{3}$ In contrast, ICAM-1 is not normallyö present at the cell surface but can be induced within hours during inflammation..$^{4-6}$ Signals? which are transduced at least partially by the ICAM-1/ $\beta_{2}$ integrin pathway include lymphocyte proliferation, antigen processing, and phagocytosis.?

Pulmonary sarcoidosis represents an example of compartmentalised inflammation, $\stackrel{\circ}{ }$ with accumulation of activated macrophages $₹$ and $\mathrm{CD} 4+$ lymphocytes in the lung. ${ }^{8-10}$ ? Central effector mechanisms of primed $>$ macrophages include the release of cytokines, reactive oxygen species, and proteases. ${ }^{11-13} \mathrm{~N}$ However, the mechanisms leading to local upregulation of the inflammation are not understood. Alveolar macrophages from ${ }^{\omega}$ patients with sarcoidosis have an increased ability to function as antigen presenting cells? (APC) and to support antigen driven prolifer- $-\infty$ ation of autologous $T$ lymphocytes, which is not due to an upregulation of HLA-DR mole-O cules on the cell surface. ${ }^{14}$ Recently the ${ }^{\mathbb{P}}$ expression of adhesion molecules on alveolar $\vec{D}$ macrophages from patients with sarcoidosiso has been reported..$^{15} 16$ The present study was undertaken to elucidate the contribution of ICAM-1 to the inflammatory process in correlation with clinical and immunologicafo parameters of disease activity in pulmonary sarcoidosis. Using a recently established ELISA method which allows semiquantitative analysis of ICAM-1 levels on alveolar macrophages as well as immunocytochemical 
staining, we determined ICAM-1 expression in a group of untreated patients with pulmonary sarcoidosis and a group of healthy volunteers.

\section{Methods \\ STUDY POPULATION}

The study population consisted of 17 consecutive untreated patients with biopsy proven pulmonary sarcoidosis (radiological type 0 , $\mathrm{n}=1$; type I, $\mathrm{n}=9$; type II, $\mathrm{n}=7$ ). There were 10 patients with active and seven with inactive disease. The assessment of clinical disease activity was performed according to previously published criteria. ${ }^{8}$ Briefly, new or increasing respiratory or systemic symptoms, a reproducible decline in vital capacity and/or diffusing capacity of $>10 \%$, and new or progressing infiltrates in the chest radiograph were accepted as signs of active disease (table 1). Six healthy volunteers were studied as controls. There were no smokers in either group which is notable as smoking influences expression of adhesion molecules. ${ }^{17}$ Ethical committee approval and individual informed consent were obtained. Clinical data and bronchoalveolar lavage cell counts are summarised in table 2 .

\section{BRONCHOALVEOLAR LAVAGE AND CELL ISOLATION}

Bronchoalveolar lavage was performed from the middle lobe using a flexible fibreoptic bronchoscope under standard conditions. ${ }^{18}$ The lavage volume was $200 \mathrm{ml}$ with a mean recovery of $84 \%$, which was similar in patients and controls. The first $20 \mathrm{ml}$ aliquot of the lavage fluid which is known to be contaminated by bronchial secretions ${ }^{19}$ was discarded and aliquots were pooled. A total cell count was made by a haemocytometer

Table 1 Clinical characteristics of patients with active and inactive sarcoidosis

\begin{tabular}{|c|c|c|}
\hline & Active & Inactive \\
\hline \multicolumn{3}{|l|}{ Chest radiograph } \\
\hline progressing & 0 & 0 \\
\hline stable & 1 & 0 \\
\hline \multicolumn{3}{|l|}{ Type I } \\
\hline progressing & 6 & 0 \\
\hline stable & 1 & 2 \\
\hline \multicolumn{3}{|l|}{ Type II } \\
\hline progressing & 2 & 0 \\
\hline stable & 0 & 5 \\
\hline \multicolumn{3}{|l|}{ Lung function* } \\
\hline \multicolumn{3}{|l|}{ Vital capacity } \\
\hline decreasing & 5 & 0 \\
\hline stable & 5 & 6 \\
\hline \multicolumn{3}{|l|}{ Diffusing capacity } \\
\hline decreasing & 7 & 0 \\
\hline stable & 3 & 6 \\
\hline Respiratory symptoms & 7 & 1 \\
\hline \multicolumn{3}{|l|}{ Systemic symptoms } \\
\hline Fever & 5 & 0 \\
\hline Erythema nodosum & 4 & $\mathbf{0}$ \\
\hline Arthritis/arthralgia & 8 & 0 \\
\hline \multicolumn{3}{|l|}{ Extrathoracic sarcoidosis } \\
\hline Uveitis & 1 & 0 \\
\hline Skin involvement & 1 & 0 \\
\hline
\end{tabular}

$\star$ Data available only for 16 patients.
Table 2 Age, sex, and cell counts in bronchoalveolar lavage (BAL) fluid of patients and healthy volunteers

\begin{tabular}{lll}
\hline & $\begin{array}{l}\text { Patients } \\
(n=17)\end{array}$ & $\begin{array}{l}\text { Controls } \\
(n=6)\end{array}$ \\
\hline $\begin{array}{l}\text { Mean (SD) age (years) } \\
\text { Sex (M:F) }\end{array}$ & $38 \cdot 2(15)$ & $27(4)$ \\
BAL fluid & $6: 11$ & $6: 0$ \\
$\quad$ Total cell count ( $\left.11^{6}\right)$ & $23(21)$ & $11(3)$ \\
Alveolar macrophages (\%) & $70(18)$ & $90(7)$ \\
Granulocytes (\%) & $1(1)$ & $1(1)$ \\
Eosinophils (\%) & $1(1)$ & \\
Lymphocytes (\%) & $28(19)$ & $8(5)$ \\
CD4+ (\%) & $81(7)$ & \\
CD4+ /CD8+ & $8 \cdot 8(4 \cdot 6)$ & \\
\hline
\end{tabular}

(Neubauer), then lavage cell differentials were determined by Wright-Giemsa stains of cytocentrifuge preparations (Cytospin II, Shandon). Cell viability was assessed using trypan blue dye exclusion. For differentiation of lymphocyte subsets (CD3, CD4, CD8) fluorescein conjugated monoclonal antibodies (Ortho Diagnostics, Beerse, Belgium) were used. Lavage cells were washed twice with phosphate buffered saline and resuspended at a concentration of $1 \times 10^{6}$ alveolar macrophages/ml in M199 supplemented with fetal calf serum ( $5 \%$, Gibco), L-glutamine (2 $\mathrm{mmol} / \mathrm{l}, \mathrm{Gibco}$ ), and penicillin/streptomycin (1 mg/ml, Gibco).

\section{ICAM-1 EXPRESSION ON ALVEOLAR}

MACROPHAGES AND LYMPHOCYTES

ICAM-1 expression on alveolar macrophages was determined by a sandwich ELISA technique. Mononuclear lavage cells containing viable alveolar macrophages at a density of 1 $\times 10 \% \mathrm{ml}$ were seeded into 96 -well flat bottom microtitre plates (Greiner, Nürtingen, Germany) for three hours $\left(37^{\circ} \mathrm{C}, 5 \%\right.$ carbon dioxide), allowing the macrophages to adhere. Non-adherent cells were removed by gentle washing and serum-supplemented M199 was added. Incubation was continued for 16 hours at $37^{\circ} \mathrm{C}$ in a total humidified atmosphere containing $5 \%$ carbon dioxide. Cells were then fixed with $1 \%$ paraformaldehyde (one hour, $21^{\circ} \mathrm{C}$ ) and free binding sites were blocked by adding a $2 \%$ solution of bovine serum albumin (BSA) diluted in phosphate buffered saline (PBS, $0.1 \mathrm{~mol} / \mathrm{l}$, $\mathrm{pH} 7 \cdot 2)$ for one hour $\left(37^{\circ} \mathrm{C}\right)$. The monoclonal mouse anti-ICAM-1 antibody (clone 84H10, Dianova, Hamburg, Germany, $1: 1000$ in $0.1 \%$ BSA/PBS) was added for two hours at $37^{\circ} \mathrm{C}$. Peroxidase conjugated goat antimouse antibody (Sigma, Deisenhofen, Germany, $1: 1000$ in $0.1 \%$ BSA/PBS) was used as developing antibody. Finally, ABTS (Sigma, $1 \mathrm{mg} / \mathrm{ml}$ ) and hydrogen peroxide $\left(2 \cdot 8 \mu \mathrm{l}, 30 \% \mathrm{H}_{2} \mathrm{O}_{2} / 10 \mathrm{ml}\right)$ in $0.1 \mathrm{~mol} / 1$ sodium acetate $(\mathrm{pH} 4 \cdot 2)$ was added. The colour was allowed to develop for 120 minutes and plates were read with a microplate reader (Behring EL 311) 405 nm.

Results were expressed as ELISA units (EU) from quadruplicate wells after subtraction of non-specific background absorbance which was determined in the absence of the 
primary antibody. The number of adherent cells at the time of the ELISA was assessed in parallel wells by crystal violet staining. Using this method we found no differences between the three groups of our study (data not shown)

In addition, ICAM-1 expression on bronchoalveolar cells was determined by immunocytochemical staining on cytocentrifuge preparations using the alkaline phosphatase monoclonal mouse antialkaline phosphatase (APAAP) complex as described. ${ }^{20}$

\section{SOLUBLE ICAM-1 (SICAM-1) SERUM LEVELS}

Serum was collected at the time of bronchoalveolar lavage and frozen at $-20^{\circ} \mathrm{C}$. sICAM1 levels were determined with a commercially available kit (Serva, Heidelberg, Germany).

\section{TNF $a$ BIOASSAY}

Tumour necrosis factor $a$ (TNFa) activity was measured with an L929 fibroblast lytic assay as previously described. ${ }^{21}$ Briefly, L929 cells $\left(6 \times 10^{4}\right.$ well) were cultured in 96-well flat bottom microtitre plates (Nunc) containing serial dilutions of conditioned supernatant of sarcoid alveolar macrophages in the presence of actinomycin D. After 20 hours of incubation the remaining cells were stained with crystal violet. The TNF $a$ concentration

Figure 1 ICAM-1 expression of alveolar macrophages from patients $(n=17)$ with active $(n=10)$ or inactive $(n=7)$ disease and healthy volunteers $(n=6)$ as determined by ELISA. $\star_{p}<0.05 v$ control.
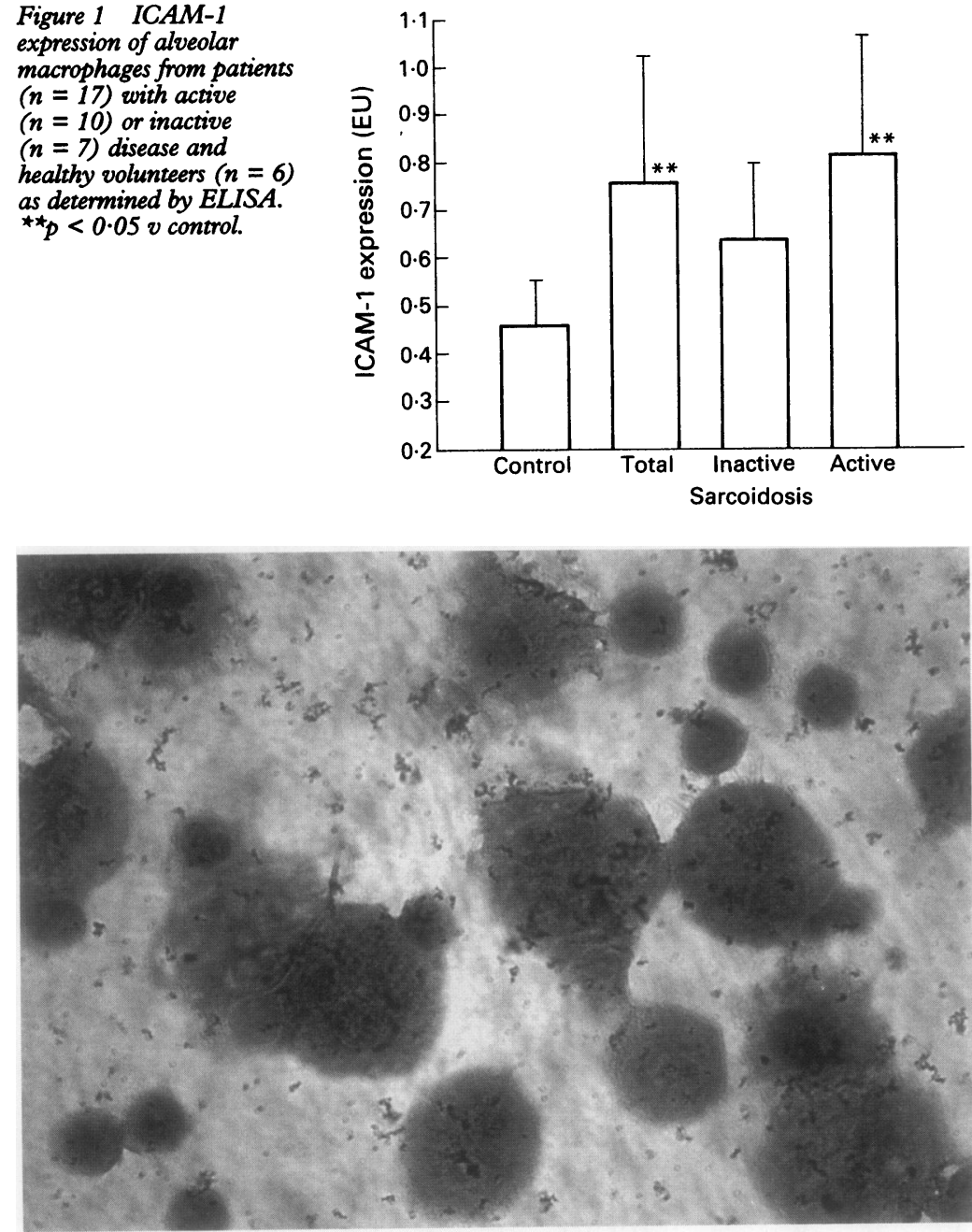

Figure 2 Immunoalkaline phosphatase (APAAP) staining on cytospin preparations of alveolar cells from patient with sarcoidosis. Original magnification $\times 630$, reduced to $82 \%$ during origination. of the samples was quantified by comparing the results with the linear portion of a standard curve obtained with human recombinant TNFa (Serva, Heidelberg, Germany, specific activity $6.6 \times 10^{6}$ units $/ \mathrm{mg}$ ). The specificity of this bioassay was tested by neutralising peak samples with a goat antihuman TNF $a$ antibody (obtained through H Biermann, Bad Nauheim, Germany from British Biotechnology).

\section{SUPEROXIDE ANION}

The production of superoxide anion was determined by a ferricytochrome c microassay. ${ }^{22}$ Briefly, $10^{5}$ alveolar macrophages were incubated in a 96-well microtitre plate with $100 \mu \mathrm{mol}$ ferricytochrome $\mathrm{c} \pm 0.2 \mathrm{mg} / \mathrm{ml}$ superoxide dismutase, with or without $10 \stackrel{\overrightarrow{\times}}{\vec{x}}$ mmol sodium fluoride or $100 \mathrm{nmol}$ PMA. All experiments were done in triplicate. Optical density was determined at $550 \mathrm{~nm}$ over a period of two hours at 30 minute intervals on a microplate reader.

\section{STATISTICS}

Non-parametric statistics were used throughout the study. The Mann-Witney U test was used for independent samples. Correlations were made with the Spearman rank correlation, using the median as a marker of central tendency. Differences were considered significant at $\mathrm{p}<0 \cdot 05$. $^{23}$

\section{Results}

TOTAL AND DIFFERENTIAL CELL COUNT

Table 2 shows the cell counts in bronchoalveolar lavage fluid. The total number of cells recovered from the bronchoalveolar lavage fluid was increased in patients with pulmonary sarcoidosis. Furthermore, the percentage of lymphocytes was significantly increased compared with the healthy controls $(\mathrm{p}<0.005)$.

ICAM-1 ON ALVEOLAR CELLS AND SERUM LEVELS OF SICAM-1

ICAM-1 expression could be detected on alveolar macrophages in all cases (fig 1). N Significantly elevated expression was seen on alveolar macrophages from patients with 0 sarcoidosis compared with controls (mean $\mathrm{\omega}$ (SD) $0.74(0.24)$ EU $v 0.46(0.12) \mathrm{EU}, \mathrm{p}<$ 次 $0.05)$. Only patients with apparently active disease showed significantly increased ICAM1 levels on alveolar macrophages $(0.82(0.27)$ EU) compared with alveolar macrophages 0 from the controls.

Immunocytochemical staining confirmed $\frac{?}{\Phi}$ the results of the ELISA for the macrophage $\frac{\sigma}{\sigma}$ population in the bronchoalveolar lavage fluid. Using the APAAP complex, ICAM-1응 expression could also be demonstrated on alveolar lymphocytes from patients with sarcoidosis (fig 2).

Serum levels of sICAM-1 ranged from 200 to $700 \mathrm{ng} / \mathrm{ml}$ and were similar in patients and controls $(490(130) \mathrm{ng} / \mathrm{ml} v 320(90) \mathrm{ng} / \mathrm{ml}$ ). 
Table 3 Mean (range) data of macrophage activation in bronchoalveolar lavage fluid of patients with active and inactive saripidosis and healthy controls

\begin{tabular}{lllll}
\hline & & \multicolumn{2}{l}{ Sarcoidosis } & \\
\cline { 3 - 5 } & Control & Total & Active & Inactive \\
\hline $\mathrm{ICAM}-1\left(\mathrm{EU} / 10^{5} \mathrm{AM}\right)$ & $0 \cdot 46(0 \cdot 29-0 \cdot 57)$ & $0 \cdot 78(0 \cdot 42-1 \cdot 17)$ & $0 \cdot 82(0 \cdot 44-1 \cdot 17)$ & $0 \cdot 64(0 \cdot 42-0 \cdot 84)$ \\
$\mathrm{TNF}\left(\right.$ units $\left./ 10^{6} \mathrm{AM}\right)$ & $3(0-10)$ & $239(5-1345)$ & $319(6-1345)$ & $59(5-141)$ \\
$\mathrm{O}_{2}^{-}\left(\mathrm{nmol} / 10^{5} \mathrm{AM}\right)$ & $0 \cdot 76(0-1 \cdot 40)$ & $2 \cdot 59(0 \cdot 37-4 \cdot 79)$ & $2 \cdot 52(1 \cdot 0-4 \cdot 79)$ & $2 \cdot 75(0 \cdot 37-3 \cdot 97)$ \\
\hline
\end{tabular}

ICAM-1-intercellular adhesion molecule 1; EU-ELISA unit; TNF $a$-tumour necrosis factor $\alpha$; $\mathrm{O}_{2}^{-}-$superoxide anion; AM-alveolar macrophage.

No correlation between sICAM-1 levels and ICAM-1 surface expression on alveolar macrophages was demonstrated.

\section{RELEASE OF TNF $a$ AND OXIDANTS BY ALVEOLAR MACROPHAGES}

All alveolar macrophages from patients with sarcoidosis spontaneously released TNF $a$ and free oxygen radicals whereas only a small amount of activity was detected in the supernatants of controls (table 3). TNFa release of alveolar macrophages correlated strongly with the ICAM-1 surface expression of those cells $(r=0.69, \mathrm{p}<0.05$; fig 3$)$. The spontaneous release of free oxygen radicals was significantly elevated in patients and did not differ between subjects with active and inactive disease (table 3 ). No correlation with ICAM-1 expression could be shown.

The intensity of the lymphocytic alveolitis as assessed by absolute numbers and percentage of $\mathrm{CD} 4+$ lymphocytes in bronchoalveolar lavage fluid was not related to the enhanced expression of ICAM-1 on alveolar macrophages.

\section{Discussion}

Pulmonary sarcoidosis is an inflammatory disorder of unknown aetiology, characterised by a mononuclear cell alveolitis and noncaseating granulomas, leading in some cases to interstitial fibrosis. ${ }^{24-26}$ To elucidate the possible role of adhesion molecules in this disease, we investigated the contribution of ICAM-1 to the process of recruitment and activation of inflammatory cells in the lung.

ICAM-1 levels on alveolar macrophages were elevated in patients with pulmonary sarcoidosis. This increase was statistically significant only in patients with active disease.

Figure 3 Correlation between the spontaneou release of TNFa and ICAM-1 surface expression of alveolar macrophages in sarcoidosis.
No other statistical difference between the two groups of patients could be established, which is probably due to the limited number of subjects in our study.

There are several possible mechanisms leading to the increased ICAM-1 levels we measured. One could be enhanced recruitment of blood monocytes into the pulmonary compartment. In a recent study by Melis et al, however, no relation between ICAM-1 expression and different blood monocyte associated markers on alveolar macrophages was found. ${ }^{15}$ Furthermore, they found no difference between ICAM-1 expression on blood monocytes from patients with sarcoidosis and from healthy volunteers. This is in line with our findings that serum levels of sICAM-1 were similar in our patients and controls.

TNF $a$ activity in the supernatant of alveolar macrophages correlated strongly with ICAM-1 surface expression of those cells. It has been shown previously that TNF $a$ and other cytokines induce ICAM-1 on endothelial cells, whereas airway epithelial cells are predominantly responsive to $\tau$-interferon. ${ }^{2 \tau}$ We recently showed that $\mathrm{TNF} a$ induces ICAM-1 on control alveolar macrophages in vitro (unpublished observation). Thus, it seems likely that in sarcoidosis ICAM-1 expression on alveolar macrophages is regulated in an autocrine manner, supporting the concept that alveolar macrophages are pivotal cells in the pathogenesis and maintenance of the inflammatory process in the pulmonary compartment. Further support for a local upregulation of ICAM-1 was that serum levels of SICAM-1 were not related to the activation demonstrated on alveolar macrophages.

Few studies exist which describe elevated ICAM-1 levels on alveolar macrophages in patients with sarcoidosis. ${ }^{1516}$ However, to our knowledge this is the first description of increased ICAM-1 expression in correlation with other parameters of immunological activity. We found no correlation between upregulated ICAM-1 expression of alveolar macrophages to the number of $\mathrm{CD} 4+$ lymphocytes in bronchoalveolar lavage fluid, which is in agreement with previous work. ${ }^{15}$ Elevated ICAM-1 surface expression was not restricted to alveolar macrophages in patients with sarcoidosis, however, but could also be demonstrated on alveolar lymphocytes. ${ }^{28}$ This suggests that the interaction between ICAM1 and its ligands on macrophages and CD4 + lymphocytes functions reciprocally. 
Considering the strong correlation we found between ICAM-1 expression and TNF $a$ secretion of the activated macrophages, we conclude that upregulated ICAM1 levels reflect disease activity in the pulmonary compartment. The fact that we could not show a correlation with the number of CD4 + lymphocytes agrees with other studies, suggesting different mechanisms of activation for the lymphocytic and macrophage component of the mononuclear cell alveolitis in pulmonary sarcoidosis. ${ }^{15} 24$

It is not clear whether upregulated ICAM1 expression on alveolar macrophages is an early event during the development of the mononuclear cell alveolitis or a result of the inappropriate cytokine secretion of alveolar macrophages and lymphocytes in the pulmonary compartment. Further research is needed to characterise the exact position of ICAM-1 in the inflammatory cascade in sarcoidosis.

The authors acknowledge the expert technical assistance of Birgitta Karlberg and Monika Losch.

1 Wawryk SO, Novotny JR, Wicks IP, Wilkinson D, Maher D, Salvaris E, et al. The role of the LFA-1/ICAM-1 interaction in human leukocyte homing and adhesion Immunol Rev 1989;108:135-61.

2 Makgoba MW, Bernard A, Sanders ME. Cell adhesion/signalling: biology and clinical applications. Eur f Clin Invest 1992;22:443-53.

3 Springer TA. Adhesion receptors of the immune system. Nature 1990;346:425-34.

4 Wegner CD, Gundel RH, Reilly P, Haynes N, Letts LG Rothlein R. Intercellular adhesion molecule-1 (ICAM1) in the pathogenesis of asthma. Science 1990; 247:456-9.

5 Malizia G, Calabrese A, Cottone $M$, Raimondo $M$, Treidosiewicz LK, Smart CJ, et al. Expression of leukocyte adhesion molecules by mucosal mononuclear phagocytes in inflammatory bowel disease: immunohistological evidence for enhanced antigen presenting capacity. Gastroenterology 1991;100:150-9.

6 Müller GA, Markovic-Lipovski J, Müller CA. Intercellula adhesion molecule-1 expression in human kidneys with glomerulonephritis. Clin Nephrol 1991;36:203-8.

7 Arnaout MA. Structure and function of the leukocyte adhesion molecules CD11/CD18. Blood 1990;75: 1037-50.

8 Müller-Quernheim J, Pfeifer S, Männel D, Strausz J, Ferlinz R. Lung-restricted activation of the alveolar macrophage/monocyte system in pulmonary sarcoidosis. Am Rev Respir Dis 1992;145:187-92.

9 Crystal RG, Bitterman PB, Rennard SI, Hance AJ, Keogh BA. Interstitial lung disease of unknown cause: disorder characterized by chronic inflammation of the lower respiratory tract. N Engl ₹ Med 1984;310:154-66, 235-44.

10 Semenzato G. The immunology of sarcoidosis. Semin Respir Med 1986;8:17-29.

11 Bachwich PR, Lynch JP III, Larrick JW, Spengler M, Kunkel SL. Tumor necrosis factor production by human sarcoid alveolar macrophages. Am $\mathcal{F}$ Pathol 1986;125:421-5.

12 Aerts C, Wallaert B, Grobois JM, Voisin C. Release of superoxide anion by alveolar macrophages in pulmonary sarcoidosis. Ann NY Acad Sci 1986;465:192-200.

13 Dalhoff K, Braun J, Lipp R, Schnabel A, Wießmann KJ. के Sauerstoffradikalbildung bei pulmonaler Sarkoidose. Dtsch Med Wschr 1992;117:887-92.

14 Ina $Y$, Takada $K$, Yamamoto $M$, Morishita $M$, Miyachi A. Antigen-presenting capacity in patients with sarcoidosis. Chest 1990;98:911-6.

15 Melis M, Gjomarkaj M, Pace E, Malizia G, Spatafora M. Increased expression of leukocyte function associated antigen-1 (LFA-1) and intercellular adhesion molecule1 (ICAM-1) by alveolar macrophages of patients with pulmonary sarcoidosis. Chest 1991;100:910-6.

16 Stritz I, Wang YM, Kalaycioglu O, Costabel U. Expression of alveolar macrophage adhesion molecules in pulmonary sarcoidosis. Chest 1992;102:882-6.

17 Hoogsteden HC, van Hal PTW, Wijkhuijs JM, Hop W, ? Verkaik APK, Hivering C. Expression of the $\infty$ CD11/CD18 cell surface adhesion glycoprotein family on alveolar macrophages in smokers and nonsmokers. Chest 1991;100:1567-71.

18 Crystal RG, Reynolds HY, Kalica AR. Bronchoalveolar $\overrightarrow{\overrightarrow{0}}$ lavage. Chest 1996;90:120-33.

19 Kelly CA, Ward C, Stenton SC, Hendrick DJ, Walters EH. Assessment of pulmonary macrophage and neutrophil function in sequential bronchoalveolar lavage aspirates in sarcoidosis. Thorax 1988;43:787-91.

20 Erber WN, Pinching AJ, Mason DY. Immunocytochemical detection of $T$ and $B$ cell populations in routine blood smears , Lancet 1984;i:1042-6.

21 Feist W, Ulmer AJ, Musehold J, Brade H, Kusumoto S, Flad H-D. Induction of tumor necrosis factor-alpha release by lipopolysaccharide and defined lipopoly- $\bullet$ saccharide partial structures. Immunobiology 1989;179: 293-307.

22 Pick E. Microassay for superoxide anion and hydrogen peroxide production and nitroblue tetrazolium reduction using an enzyme immunoassay microplate reader. Method Enzymol 1986;132:407-21.

23 Sachs L. Angewandte Statistik. Berlin: Springer Verlag, 1984:230-8.

24 Keogh A, Hunninghake GW, Line BR, Crystal RG. The alveolitis of pulmonary sarcoidosis. Am Rev Respir Dis $\mathrm{O}$ 1983;128:256-65.

25 Thomas PD, Hunninghake GW. Current concepts in the pathogenesis of sarcoidosis. Am Rev Respir Dis 1987; 135:747-60.

26 Saboor SA, McI Johnson N, McFadden J. Detection of mycobacterial DNA in sarcoidosis and tuberculosis with polymerase chain reaction. Lancet 1992;339:1012-5.

27 Look DC, Rapp SR, Keller BT, Holtzmann MJ. Selective induction of intercellular adhesion molecule-1 by inter- $O$ feron-U் in human airway epithelial cells. Am $\mathcal{f}$ Physiol 1992;263:L79-L87.

28 Nagai S, Satake N, Kaneshima H, Kawatani A, Takeuchi M, Izumi T. Expression of adhesion molecules on lung $\mathrm{T}$ cells and macrophages in patients with pulmonary음 sarcoidosis. Eur Respir f 1992;5(Suppl):501s. 